\title{
Effects of obesity on metabolic and cardiovascular outcomes following insulin initiation in patients with Type 2 Diabetes
}

\author{
[Manuscript]
}

\section{Uchenna Anyanwagu, Jil Mamza, Richard Donnelly, Iskandar Idris}

Division of Medical Sciences \& Graduate Entry Medicine

School of Medicine, University of Nottingham, UK

Running Title: Outcome in obese Type 2 diabetes on insulin

Keywords: Type 2 diabetes, obesity, Insulin, cardiovascular, mortality

Funding source: None. (Departmental funds)

Conflict of interest: None declared for all authors relating to this publication

Correspondence:

Dr Iskandar Idris

Division of Medical Sciences \& Graduate Entry Medicine,

School of Medicine, University of Nottingham,

Royal Derby Hospital, Uttoxeter Road,

Derby DE22 3DT, UK

Email: Iskandar.idris@ nottingham.ac.uk

Tel: 01332724668

Word count

Abstract:200

Main text: 3200

Tables: 4

Figures:3 


\section{What is already known about this subject?}

1) Insulin therapy is the most effective therapy to lower HbA1c levels but is well recognised to be associated with weight gain

2) Weight gain and obesity is a recognized risk factor for the development of type 2 diabetes, and adverse cardiovascular outcomes.

\section{What does this study add?}

1) Despite the well-recognised correlation between obesity, exogenous hyperinsulinaemia and $\mathrm{CV}$, there is little direct evidence relating to the impact of baseline obesity on metabolic and mortality outcomes following insulin initiation in routine clinical practice.

2) In the short term, increasing level of obesity is significantly associated with reduced likelihood of achieving target HbA1c levels, but this observation was not significant in the longer term

3) Patients with morbid obesity who are started on insulin therapy is associated with a $30 \%$ increased risk of developing adverse cardiovascular outcomes 


\section{Abstract}

Objectives: Insulin therapy induces weight gain but whether it causes long term adverse metabolic and CV outcomes in obese patients remains unclear.

Methods: A retrospective cohort study of 12,725 insulin initiators with T2D derived from UK General Practices. Multivariate linear, logistic regression analyses and Cox proportional hazard models were used to estimate $\mathrm{HbA1c}$, BMI, risk of composite $\mathrm{CV}$ events between baseline BMI categories at 5 years.

Results: Mean age was $58.6 \pm 13.8$ years. The proportion of patients achieving HbA1c targets decreased across increasing BMI categories at 6 and at 12 months; $p=0.0001$, but not significant beyond 24 months. 1,095 composite events of all-cause mortality, non-fatal stroke and MI occurred with an adjusted hazard risk (aHR) relative to normal of : (1.10; 95\%CI: $0.90-1.35)$ in the overweight, $(1.05 ; 95 \% \mathrm{CI}$ : 0.86-1.29) in the obese class I, $(1.03$; 95\%CI: $0.83-1.29)$ in the obese class II and (1.30; 95\%CI: 1.02-1.66) in the obese class III BMI categories.

Conclusion: Among patients with T2D insulin initiators, obesity adversely influence HbA1c up to 12 months, but not beyond 24 months and is associated with a decrease in BMI compared to non-obese groups. Morbidly obese patients initiating insulin have 30\% increased risk of composite CV events after 5 years. 


\section{Introduction:}

In the UK, obesity is estimated to affect 1 in every 4 adults[1], is prevalent in patients with type 2 diabetes (T2D) worldwide [2,3] and is recognised to be associated with adverse cardiovascular (CV) events including mortality[4]. The therapeutic management of T2D aims at maintaining good glycaemic control in order to minimise long-term vascular complications but in the obese population, balancing the appropriate choice of therapy with the unintended effects such as weight gain presents a dilemma and therefore needs to be individualised [5]. Insulin therapy is the most effective therapy to lower Glycated Haemoglobin (HbA1c) levels but is well recognised to be associated with weight gain [6]. In the United Kingdom Prospective Diabetes Study (UKPDS), patients in the intensive intervention cohort was observed to gain approximately $5 \mathrm{~kg}$ during the 10 -year follow-up period, with most of this gain occurring in the first 12 months. [7] We and others have also shown that in routine clinical practice, the effectiveness of insulin therapy to lower HbA1c levels is dependent on patients' baseline weight $[8,9]$, and is speculated to be due to insulin-induced weight gain resulting in an increase in the amount of insulin required to control hyperglycaemia [10,11] at the expense of further weight gain, possible poor treatment compliance and increased insulin resistance.

Despite the well-recognised correlation between obesity, exogenous hyperinsulinaemia and $\mathrm{CV}$ risk [12], there is little direct evidence relating to the impact of baseline obesity on mortality outcomes following insulin initiation in routine clinical practice. However, there is indirect evidence that weight gain does adversely affect $\mathrm{CV}$ risk. The ACCORD study designed to investigate whether an aggressive therapeutic strategy to achieve tight glucose target (HbA1c $<6.5 \%$ ) would reduce CV events surprisingly showed an increased mortality in the intensively treated group [13], with weight gain by more than $10 \mathrm{~kg}$ occurred in $27.8 \%$ of the intensively treated patients compared with $14.1 \%$ in the standard therapy. While no causal relationship 
between obesity and adverse CV outcomes can be assumed, other retrospective studies have shown that people with diabetes who actively lose weight improve not only their risk profile [14-16] but also survival rate. Previous similar studies focusing on the association between obesity at insulin initiation were limited by either by their choice of patients as in the UKPDS which used predominantly obese patients; [7] study population size; [6]; the exclusion of younger patients with T2D, short follow up period, or failure to adjust for important risk factors associated with obesity [17].

To our knowledge, no real-world study has explored the long-term effects of obesity at insulin initiation on metabolic and CV outcomes. So, we aimed therefore to investigate the association between obesity, metabolic outcomes (HbA1c and weight), CV events and mortality in patients with T2D who initiated insulin therapy. 


\section{Methods:}

\section{Study Design and Data Source:}

This was a retrospective cohort study using data derived from the UK anonymised longitudinal electronic Primary Care data called The Health Improvement Network (THIN). This database has details of over 12.4 million patients (3.61 million currently active) from about 587 UK general practices. It has been validated and shown to be representative of the UK population in terms of demography, life-event rates and other health-related events; and has been extensively used in diabetes-related researches. [18-20] Anonymised records on all insulin users with type 2 diabetes (T2D) between December 1, 2007 and May 31, 2014 were obtained and data on HbA1c levels, height, weight, socio-demographic variables, prescriptions of glucose-lowering medications, other medication prescriptions, and co-morbidities between 180 days before insulin initiation to 5 years after initiation were extracted.

\section{Selection Criteria and Study Population:}

The patient cohort was selected based on the following criteria at the index date of insulin initiation: age $\geq 18$ years; records of diagnosis of T2D (identified by their appropriate ICD-10 codes) made a minimum of 180 days before index date and continuous prescription of insulin beyond 180 days after index date. Patients with identifiable ICD-10 codes for type 1 diabetes, gestational or other forms of diabetes, or with no identifiable continuous insulin prescription in their records were excluded. Insulin regimens are classed as premixed insulin (combination of short acting and long acting insulin in a prefilled pen) and basal bolus insulin (combination of any long acting insulin injected any time with at least one short acting insulin with meal)

\section{Study Exposure and Outcomes:}

The main exposure was the baseline BMI [weight $(\mathrm{kg}) /($ height $(\mathrm{m}) \mathrm{x}$ height $(\mathrm{m}))$ ]. This was assessed from 0 to 90 days before the index date. BMI was classified thus: normal (BMI $\leq$ 24.9kg/m²), overweight (BMI: $25.0-29.9 \mathrm{~kg} / \mathrm{m}^{2}$ ), obese/obese class I (BMI: $30.0-34.9 \mathrm{~kg} / \mathrm{m}^{2}$ ), 
clinically obese/obese class II (BMI: $35.0-39.9 \mathrm{~kg} / \mathrm{m}^{2}$ ) and morbidly obese/obese class III (BMI: $\left.\geq 40.0 \mathrm{~kg} / \mathrm{m}^{2}\right)$.

The primary outcomes were i) changes in HbA1c, weight and BMI from baseline to 6, 12, 24, 36, 48 and 60 months post index date; and ii) proportion of patients achieving a target $\mathrm{HbA} 1 \mathrm{c}$ of $\leq 7.5 \%$ at these time intervals, stratified by BMI at index date. Post-index date HbA1c, weight and BMI values were assessed at 6 months and later at yearly intervals till a maximum of 5 years after index date. Where more than one recording of a variable was noted within each time interval, the mean value was computed and recorded for that review date. Secondary outcome was the risk of a three-point composite of Major Adverse Cardiovascular Events (MACE), comprising of non-fatal myocardial infarction (MI), non-fatal stroke and all-cause mortality between the baseline BMI categories. In estimating this risk, patients were followed up from the point of insulin initiation (index date) and censored at the earliest occurrence of any of the following outcomes - discontinuation of insulin, occurrence of MACE, loss to follow-up, and-at the end of the study at 5 years. The time (t) to any of these outcomes was determined for each patient, as well as the event of MACE (d) which occurred within this time interval. These were fitted in a Cox regression model.

\section{Covariates:}

Significant a priori confounders which could impact on glycaemic control, change in weight and BMI, and the risk of MACE were extracted at baseline and adjustment was made for these in the multivariate linear and Cox regression models. These include demographic variables as age, gender, socioeconomic status (derived by the Townsend deprivation (21) scores and ranked in quintiles from the least, to the most deprived area), alcohol (drinker defined as currently consuming any amount of alcohol per week) and smoking status. Others were clinical measures as systolic and diastolic blood pressure, diabetes duration before index date, duration of use of other glucose-lowering therapies (GLTs), use of antihypertensives and lipid-lowering 
therapies (LLTs), co-morbidity status and laboratory measures as creatinine level, lipid-profile (total cholesterol, high density lipoprotein, low density lipoprotein, and triglycerides), glomerular filtration rates (eGFR), and albumin level.

\section{Statistical Methods}

A small proportion of patients had missing records for $\mathrm{HbA} 1 \mathrm{c}$, weight and height at different time intervals. These variables were uniformly distributed and completely missing at random. Multiple imputations using the chained equation (MICE) model was used to account for these missing data and the imputed (complete) data were used for all analyses. The baseline characteristics of the study cohort was first summarised as the mean (with standard deviation) and as absolute values (with proportions) stratified by BMI category at baseline.

A univariate linear regression model was used to test the association between these baseline covariates and the study exposure and outcomes in order to adjust for any confounding effect they may have on the study outcomes. Covariates which were found to be significantly associated $(\mathrm{p}<0.05)$ with the study exposure and outcomes were selected for inclusion in the

multivariate model. So, for the primary outcomes of changes in HbA1c, weight and BMI, a multivariate repeated-measures linear regression model was fitted with their values at 6,12 , 24, 36, 48 and 60 months to estimate changes from index date. Pearson's Chi-square test was used to estimate the proportion achieving an $\mathrm{HbA} 1 \mathrm{c}$ target of $\leq 7.5 \%$ at each time interval.

To estimate the hazard of MACE, crude and adjusted Kaplan-Meier estimates of survival functions between the BMI categories were calculated and the log-rank test was used to compare the equality of the survival curves between them. From these survival functions, we computed the absolute reduction in the probability of the incidence of the all-cause mortality within a 5-year follow-up. Finally, a Cox proportional hazard model to estimate the marginal 
and adjusted hazard of MACE in all the BMI groups (treated groups), compared to the normal BMI group. Any violations in the proportional hazards assumptions were confirmed with Schoenfeld residuals tests.

\section{Sensitivity and Subgroup analyses}

To explore the impact the missing values may have on the overall outcome and assess the robustness of our imputation, all the analyses were repeated in the dataset with missing values and the study outcomes compared. Also, subgroup analyses were done for the individual components of MACE, as well as a composite of CV events (non-fatal MI or stroke).

In all the models, the point estimates were estimated with $95 \%$ confidence intervals (CI) at the conventional statistical significance level of $<0.05$ while all analyses were conducted using Stata Software, version 14 (StataCorp. Stata Statistical Software: Release 14. College Station, TX: StataCorp LP. 2015). 


\section{Results:}

\section{Baseline demographics:}

The study population comprised 12,725 patients with T2D after the application of the inclusion and exclusion criteria on the initial 19,808 patients identified in the THIN dataset (Figure 1). There was a greater proportion of males in the normal BMI category and higher proportion of females in the obese class III BMI category $(\mathrm{p}<0.0001)$. Patients in the normal BMI category were older while those in the obese class III were younger. Conversely, baseline HbA1c and systolic blood pressure were highest and lowest in the obese class III and normal BMI categories respectively (Table 1).

\section{Association between BMI on insulin initiation and glycaemic control.}

A summary of the proportion of patients achieving the National Institute of Health and Care Excellence (NICE) target of $\leq 7.5 \%(58 \mathrm{mmol} / \mathrm{mol})$ and the odds of attaining this target compared to the normal BMI category is shown in Table 2. Compared to the normal BMI group, the odds of achieving the target $\mathrm{HbA} 1 \mathrm{c}$ significantly declined across all rising BMI levels at 6 and 12 months. On the long term, however, there was no significant difference in the proportion achieving this target beyond 24 months, neither was any significant trend observed.

Figure 2 showed the mean change in HbA1c from baseline in all BMI categories. Overall, there was a significant reduction in $\mathrm{HbA1c}$ - the greatest reduction was seen in the normal BMI category from 6 to 24 months, but beyond this period, the morbidly obese category recorded the greatest reduction. Following adjustment for age, gender, baseline $\mathrm{HbA} 1 \mathrm{c}$ and duration of diabetes, when compared to the normal BMI group, the reductions in HbA1c at 6 months were $0.10 \%$ (95\%CI: $-0.01,0.21 ; \mathrm{p}=0.075)$ in the overweight; $0.19 \%$ (95\%CI: $0.08,0.29 ; \mathrm{p}<0.001)$ in obese class I; $0.21 \%(95 \% \mathrm{CI}$ : $0.10,0.32 ; \mathrm{p}<0.001)$ in obese class II; and $0.29 \%(95 \% \mathrm{CI}$ : 
$0.17,0.42 ; \mathrm{p}<0.001)$ greater in the class III obese groups. At 12 months, the adjusted differences were slightly reduced to $0.08 \%(95 \% \mathrm{CI}:-0.02,0.19 ; \mathrm{p}=0.119)$ in the overweight; $0.17 \%(95 \%$ CI: $0.06,0.27 ; \mathrm{p}=0.001)$ in obese class I; $0.19 \%(95 \% \mathrm{CI}: 0.08,0.30 ; \mathrm{p}=0.001)$ in obese class II; and $0.25 \%(95 \% \mathrm{CI}: 0.13,0.38$; $\mathrm{p}<0.001)$ greater in the class III obese groups. Beyond 24 months, we failed to show statistical significance in the mean difference in HbA1c change between the BMI groups; such that at 60 months, the mean difference was $0.08 \%$ (95\%CI: $-0.09,0.25 ; \mathrm{p}=0.356)$ in the overweight; $0.05 \%(95 \% \mathrm{CI}:-0.12,0.21 ; \mathrm{p}=0.807)$ in obese class I; $0.06 \%(95 \% \mathrm{CI}:-0.11,0.24 ; \mathrm{p}=0.475)$ in obese class II; and $-0.002 \%$ (95\%CI: $0.20,0.19 ; \mathrm{p}=0.981$ ) greater in the class III obese groups.

\section{Association between BMI at baseline and changes in weight and BMI}

There was a consistent significant increase in weight and BMI in the normal and overweight categories throughout the study duration, while the other categories experienced a decrease ( $\mathrm{p}$ $<0.00001$ in all). Patients in the normal and overweight categories experienced increases in mean weight from $71.8 \mathrm{~kg}$ and $81.5 \mathrm{~kg}$ respectively at 6 months, to $80.7 \mathrm{~kg}$ and $85.3 \mathrm{~kg}$ ( $\mathrm{p}<$ 0.0001) at 60 months; but in the obese (classes I to III) categories, there was a significant reduction in weight from baseline at each study timeline (e.g. from $115.1 \mathrm{~kg}$ at 6 months to $103.5 \mathrm{~kg}$ at 60 months $(\mathrm{p}<0.0001)$ in the morbidly obese category). Similarly, BMI increased from $23.3 \mathrm{~kg} / \mathrm{m}^{2}$ and $28.3 \mathrm{~kg} / \mathrm{m}^{2}$ at 12 months in the normal and overweight categories respectively to $28.2 \mathrm{~kg} / \mathrm{m}^{2}$ and $30.5 \mathrm{~kg} / \mathrm{m}^{2}$ respectively at 60 months $(\mathrm{p}<0.0001)$ but other BMI categories had a significant decrease in BMI (Table 3).

The mean coefficient of change in weight compared to the normal BMI category showed greater reduction in weight and BMI across all the BMI categories, compared to the normal category at all study timelines (LRT p-values were $<0.00001$ in all). There was a significant trend ( $\mathrm{p}<0.0001)$ across the BMI categories. So, for each level of baseline BMI, there was a 
reduction in weight and BMI. For instance, our findings at 12 months shows that for each level increase in BMI category, there was a reduction of $1.4 \mathrm{~kg}(95 \% \mathrm{CI}:-1.5,-1.3 ; \mathrm{p}<0.0001)$ in weight and $0.62 \mathrm{~kg} / \mathrm{m}^{2}(95 \% \mathrm{CI}:-0.67,-0.58 ; \mathrm{p}<0.0001)$ in BMI.

Figure 3 summarise the mean change in BMI within the baseline BMI categories by the study timelines. The funnel-shape figure depict the different change patterns between the normal and overweight BMI categories vs the Obese (Classes II and III). The obese class I category maintained almost a plateau. At 60 months, the greatest reductions in weight and mean BMI were in the obese class III category (losing $12.91 \mathrm{~kg}$ and $5.66 \mathrm{~kg} / \mathrm{m}^{2}$ respectively from baseline) as against the normal category which recorded the greatest gain of $11.00 \mathrm{~kg}$ in weight and $6.32 \mathrm{~kg} / \mathrm{m}^{2}$ in BMI from baseline.

\section{Risk of Major Adverse Cardiovascular Event (MACE)}

The mean follow-up duration was 4.38 years with a total follow-up of 49,516 person-years. There is no significant difference in survival between the baseline BMI categories at 5years $(\log$-rank test $\mathrm{p}$-value $=0.228)$. There were 1,095 composite events of MACE, with a crude event rate of 22.1 per 1,000 person-years (95\%CI: 20.8, 23.5). BMI at insulin initiation was associated with a 10\% [aHR: $1.10(0.90-1.35)] ; 5 \%$ [aHR: $1.05(0.86-1.29)] ; 3 \%$ [aHR: 1.03 (0.83 - 1.29)]; and 30\% [aHR: $1.30(1.02-1.66)]$ higher risk of MACE in the overweight, obese, clinically obese and morbidly obese categories respectively, compared to the normal BMI category after adjusting for age, gender, use of LLTs and antihypertensives, comorbidities of heart failure and coronary heart disease, albumin, GFR, lipid profile (total cholesterol, low density lipoprotein cholesterol, triglyceride, high density lipoprotein cholesterol) and the use of GLP-1RA (Table 4). 
Subgroup Analysis: In the adjusted model, the risk of all-cause mortality was 9\% [aHR: 1.09 (0.81-1.45)]; 12\% [aHR: $1.12(0.84-1.49)] ; 31 \%$ [aHR: $1.31(0.96-1.77)]$; and 75\% [aHR: $1.75(1.26-2.43)]$ higher risk of MACE in the overweight, obese, clinically obese and morbidly obese categories respectively while the risks of a composite $\mathrm{CV}$ event were $25 \%$, $21 \%$, the same, and $34 \%$ higher compared to patients with normal BMI at baseline. 


\section{Discussion:}

Several conclusion could be derived from this observational study obtained from a large longitudinal real world data. Firstly, HbA1c reduction was reduced irrespective of baseline HbA1c with a marginal greater Hbalc reduction in the normal/overweight weight group in the first 2 years and obese group at 3 years of insulin treatment. Secondly, insulin induced significant weight gain among normal and overweight individuals but a paradoxical weight loss in the obese individual. Thirdly, the observed weight loss in the obese group was consistent over 12, 24 and 36 months of insulin treatment; and lastly obese patients, especially stage III obesity, was associated with an increased risk of mortality at 5 years of follow up. This study provides reassurance of the efficacy of insulin treatment in patients with $\mathrm{T} 2 \mathrm{D}$, irrespective of their baseline BMI, but highlight the high mortality risk for the obese patients with T2D.

Our findings above are robust, and are supported by separate analyses to explore possible confounders and via sensitivity analysis. This is further supported by consistent findings in patients from the entire cohort. The level of HbA1c and CV risk profile (e.g. lipid, blood pressure) were clinically similar across all weight change categories. This findings of this study was in concordance with a previous study using a US-based electronic medical record which reported a reduction in $\mathrm{HbA1c}$ was associated with progressively less weight gain as baseline BMI rose. [22]. The inference from that study that the lesser weight gain seen in obese patients was due to the use of less intensive insulin therapy may also apply to this cohort, although interestingly, we observed greater $\mathrm{HbA1c}$ reduction and paradoxical greater weight loss in the obese group, compared with the normal and overweight group at 36 months of insulin initiation. When adjusted for different confounder, we observed an overall greater HbA1c reduction in in the normal weight group and lesser weight in the overweight and obese group. 
Although we observed the association between higher mortality rate with baseline obesity at insulin initiation, our study did not infer a causative role of insulin treatment in inducing the adverse mortality outcome in obese patients. Indeed, increased body weight among obese individuals per se is recognised to lead to worsening of cardiovascular risk factors $[16,17,23]$ and in a prospective study of more than 17,000 middle-aged patients, obese patients with diabetes had a 3-fold greater risk of mortality compared to non-obese patients with diabetes, independent of their glucose lowering treatment [24]. Whether insulin induced weight gain is associated with adverse $\mathrm{CV}$ outcome remains unknown because robust large scale clinical trials such as UKPDS [7], ADVANCE [25] and ACCORD [13] study did not stratify their CV outcomes by weight-loss or weight-gain, for any given level of glycaemic control. However, in a post hoc analysis of the ACCORD study, patients who were inadequately controlled at baseline and received intensive glucose lowering strategy but still had suboptimal glucose control $(\mathrm{HbA} 1 \mathrm{c}>7 \%$; $>53 \mathrm{mmol} / \mathrm{mol})$ experienced higher mortality rate [26]. This observation suggest patient-factors associated with persistently high $\mathrm{HbA1c}$, despite intensive treatment, appear to be the most important determinant of increased mortality risks. To this end, an important confounder that needs to be considered in our observation is that insulin-induced weight gain suggest patients' compliance to insulin treatment intensification and thus a surrogate marker of compliance to holistic care and treatment.

Thus the observation from this study that obese patients experienced relative weight loss and less $\mathrm{HbA} 1 \mathrm{c}$ reduction (compared to the normal and overweight group) could potentially imply a less compliance or less aggressively managed patients. While compliance to insulin therapy may also be a factor in this observation, it might be conceivable that overweight patients were provided with more detailed advice regarding strategies to lose weight and/or a referral to dietitian, due to anticipated weight gain due to insulin, than individuals who are underweight or have normal weight. However, this observation only hold valid in the first 24 months of 
treatment, because at 36 months of treatment, there appears to be a greater relating $\mathrm{HbA} 1 \mathrm{c}$ reduction in the obese group, compared with normal or overweight. Nevertheless, we contend that that failure to achieve $\mathrm{HbA1c}$ reduction, despite optimal glucose lowering treatment, in obese patients should trigger clinicians to intensify cardiovascular risk reduction strategies.

Our analyses were subject to a number of limitations that are inherent to observational studies. Firstly, as previously discussed, we cannot ascertain treatment compliance. Also, some factors like lifestyle and dietary intervention may influence our findings. We were also not able to obtain the longitudinal insulin doses, an important predictor of insulin-induced weight gain. $[27,28]$. Difference in the use of different glucose lowering therapy is large. This however reflects the current preference of glucose lowering therapy in UK primary care, i.e. a high preference for metformin and sulfonylurea, but less experience with novel therapies like DPP4 inhibitor, GLP-1 and SGLT inhibitor). In addition, the long duration of diabetes may also account for differences in the use of GLT in this study. This may be since our aim was to look at status of baseline weight per se on metabolic and CV outcomes, we would argue that this should not influence the robustness of our findings. Although we could not account for other potential residual confounders such, indications for intensification treatments, markers of $\beta$ cell deterioration, doses of lipid lowering or antihypertensive therapy and frequency of hypoglycaemia, we were able to account for differences in the observed covariates and used robust analytical techniques to control confounding that may bias the results of the estimated treatment effects.

In conclusion, we observed that while insulin treatment is associated with weight gain, baseline weight confers only a marginal influence on its efficacy in achieving HbA1c target. Nevertheless, obese patients at the time of insulin initiation appear to be at high risk of mortality. While these findings should provide important reassurance among patients with T2D 
who gained weight following insulin treatment in routine clinical practice, it also highlights the high mortality risk of obese people with T2D. 


\section{Reference}

1. World Health Organisation (WHO). Obesity: preventing and managing the global epidemic. Report of a WHO Consultation. WHO Technical Report Series 894. Geneva: World Health Organization, 2000.

2. Freemantle N, Holmes J, Hockey A, Kumar S. How strong is the association between abdominal obesity and the incidence of type 2 diabetes? International Journal of Clinical Practice 2008; 62(9): 1391-6.

3. Garber AJ. Obesity and type 2 diabetes: which patients are at risk? Diabetes, Obesity \& Metabolism 2012; 14(5): 399-408.

4. Kim SH, Després J-P, Koh KK. Obesity and cardiovascular disease: friend or foe? European Heart Journal 2016; 37(48): 3560-8.

5. National Institute for Health and Clinical Excellence (NICE). Type 2 diabetes: the management of type 2 diabetes. NICE clinical guideline 87. 2009.

https://www.nice.org.uk/guidance/cg87/chapter/1-Guidance (accessed 10 April 2015).

6. Biesenbach G, Raml A, Alsaraji N. Weight gain and insulin requirement in type 2 diabetic patients during the first year after initiating insulin therapy dependant on baseline BMI. Diabetes, Obesity and Metabolism 2006; 8: 669-673

7. UK Prospective Diabetes Study (UKPDS) Group. Intensive blood-glucose control with sulphonylureas or insulin compared with conventional treatment and risk of complications in patients with type 2 diabetes (UKPDS 33). Lancet 1998; 352: 837853.

8. V Owen, I Seetho, I Idris. Predictors of responders to insulin therapy at one year among adults with type 2 diabetes. Diabetes Obesity Metabolism. 2010; 12:865-70.

9. Idris I, Pillai A, Fernando DJ, Thomson G, Tate H. Responders to insulin therapy at 18 months in adults with newly diagnosed diabetes: which insulin regimen? Diabetic Medicine 2013; 30(3): e95-e100.

10. Van Avendonk MWJ, Rutten GEH. Insulin therapy in type 2 diabetes: what is the evidence? Diabetes, Obesity and Metabolism. 2009; 5:415

11. Ryysy L, Häkkinen AM, Goto T, Vehkavaara S, Westerbacka J, Halavaara J, YkiJärvinen $\mathrm{H}$. Hepatic fat content and insulin action on free fatty acids and glucose metabolism rather than insulin absorption are associated with insulin requirements during insulin therapy in type 2 diabetic patients. Diabetes. 2000; 49:749-58

12. Currie CJ, Johnson JA. The safety profile of exogenous insulin in people with type 2 diabetes: justification for concern. Diabetes, Obesity and Metabolism. 2012;14(1):1-4. 
13. The Action to Control Cardiovascular risk in diabetes study Group. Effects of Intensive Glucose Lowering in Type 2 Diabetes. New England Journal of Medicine 2008; 358(24): 2545-59.

14. Anderson JW, Kendall CW, Jenkins DJ. Importance of weight management in type 2 diabetes: review with meta-analysis of clinical studies. J Am Coll Nutr. 2003; 22: 331339.

15. Khan MA, St Peter JV, Breen GA, Hartley GG, Vessey JT. Diabetes disease stage predicts weight loss outcomes with long-term appetite suppressants. Obes Res. 2000; 8: $43-48$.

16. Lean ME, Powrie JK, Anderson AS, Garthwaite PH.Obesity, weight loss and prognosis in type 2 diabetes. Diabetic Med. 1990; 7: 228-233.

17. Watson L, Wilson BP, Alsop J, Kumar S. Weight and glycaemic control in type 2 diabetes: what is the outcome of insulin initiation? Diabetes, Obesity \& Metabolism 2011; 13(9): 823-31

18. Blak BT, Thompson M, Dattani H, Bourke A. Generalisability of The Health Improvement Network (THIN) database: demographics, chronic disease prevalence and mortality rates. Informatics in Primary Care 2011; 19(4): 251-5

19. Lewis JD, Schinnar R, Bilker WB, Wang X, Strom BL. Validation studies of the health improvement network (THIN) database for pharmacoepidemiology research. Pharmacoepidemiology and Drug Safety 2007; 16(4): 393-401.

20. Anyanwagu U, Mamza J, Mehta R, Donnelly R, Idris I. Cardiovascular events and allcause mortality with insulin versus glucagon-like peptide- 1 analogue in type 2 diabetes. Heart 2016.

21. Townsend, P., Phillimore, P. and Beattie, A. Health and Deprivation: Inequality and the North. Routledge, London. 1988

22. Paul SK, Shaw J, Montvida O, Klein K. Weight gain in insulin treated patients by BMI categories at treatment initiation: New evidence from real-world data in patients with type 2 diabetes. Diabetes Obesity Metabolism. 2016 Aug 9. doi: 10.1111/dom.12761.

23. Oldridge N, Stump TE, Nothwehr FK, Clark DO. Prevalence and outcomes of comorbid metabolic and cardiovascular conditions in middle and older age adults. $\mathrm{J}$ Clin Epidemiol. 2001; 54:928

24. Cho E, Manson JE, Stampfer MJ, Solomon CG, Colditz GA, Speizer FE, Willett WC, Hu FB. A prospective study of obesity and risk of coronary heart disease among diabetic women. Diabetes Care 2002; 25:1142

25. The ADVANCE Collaborative Group. Intensive Blood Glucose Control and Vascular Outcomes in Patients with Type 2 Diabetes. New England Journal of Medicine 2008; 358(24): 2560-72.

26. Riddle MC, Ambrosius WT, Brillon DJ, Buse JB, Byington RP, Cohen RM, Goff DC Jr, Malozowski S, Margolis KL, Probstfield JL, Schnall A, Seaquist ER; Action to 
Control Cardiovascular Risk in Diabetes Investigators. Epidemiologic relationships between A1C and all-cause mortality during a median 3.4-year follow-up of glycaemic treatment in the ACCORD trial. Diabetes Care. 2010; 33(5):983-990.

27. Balkau B, Home PD, Vincent M, Marre M, Freemantle N. Factors associated with weight gain in people with type 2 diabetes starting on insulin. Diabetes Care. 2014; 37(8):2108-13.

28. Pontiroli AE, Miele L, Morabito A. Increase of body weight during the first year of intensive insulin treatment in type 2 diabetes: systematic review and meta-analysis. Diabetes, Obesity \& Metabolism. 2011; 13(11):1008-19. 


\section{Legend}

Table 1 - Baseline characteristics of study participants

Table 2 - Proportions and odds of achieving the NICE target $\mathrm{HbAlc}$ of $\leq 7.5 \%(58 \mathrm{mmol} / \mathrm{mol})$ by the BMI categories.

Table 3- Mean follow-up BMI and mean coefficients of change in BMI compared to the normal BMI category

Table 4 - Events, rates and hazard ratios of composite MACE and subgroup of all-cause mortality, non-fatal MI and stroke by baseline BMI categories.

\section{Figures}

Figure 1 - Selection of study cohort of adult (age $>18$ years) patients with type 2 diabetes

Figure 2 - Mean difference in HbA1c (\%) from baseline at 6 to 60 months by BMI categories (all p-values $<0.0001$ )

Figure 3:Mean difference in BMI $\left(\mathrm{kg} / \mathrm{m}^{2}\right)$ from baseline at 6 to 60 months by BMI categories (all p-values $<0.0001$ ) 
Table 1: Baseline characteristics of the study population

\begin{tabular}{|c|c|c|c|c|c|c|}
\hline & $\begin{array}{l}\text { Normal } \\
(n=1665)\end{array}$ & $\begin{array}{c}\text { Overweight } \\
(\mathrm{n}=3022)\end{array}$ & $\begin{array}{c}\text { Obese Class I } \\
(n=3712)\end{array}$ & $\begin{array}{c}\text { Obese Class II } \\
(n=2637)\end{array}$ & $\begin{array}{c}\text { Obese Class III } \\
(n=1689)\end{array}$ & $\begin{array}{c}\text { Total } \\
(\mathrm{n}=12,725)\end{array}$ \\
\hline \multicolumn{7}{|l|}{ Demographics } \\
\hline Age (yrs), Mean (SD) & $60.2(13.3)$ & $59.8(13.7)$ & $58.7(13.6)$ & $57.9(13.9)$ & $56.0(14.2)$ & $58.6(13.8)$ \\
\hline \multicolumn{7}{|l|}{ Gender, No. $(\%)$} \\
\hline Male & $1165(70)$ & $1799(60)$ & $1792(48)$ & $1058(40)$ & $531(31)$ & $6345(50)$ \\
\hline Female & $500(30)$ & $1223(40)$ & $1920(52)$ & $1579(60)$ & $1158(69)$ & $6380(50)$ \\
\hline \multicolumn{7}{|c|}{ Townsend deprivation index, No. (\%) } \\
\hline Least deprived & $372(23)$ & $653(23)$ & $710(20)$ & $503(20)$ & $316(20)$ & $2554(20)$ \\
\hline 2nd quintile & $336(21)$ & $612(21)$ & $716(20)$ & $505(20)$ & $302(19)$ & $2471(19)$ \\
\hline 3rd quintile & $358(22)$ & $598(21)$ & $804(23)$ & $559(22)$ & $358(22)$ & $2677(21)$ \\
\hline 4th quintile & $307(19)$ & $604(21)$ & $763(21)$ & $548(22)$ & $348(22)$ & $2570(20)$ \\
\hline Most deprived & $229(14)$ & $412(14)$ & $574(16)$ & 419 (17) & $284(18)$ & $1918(15)$ \\
\hline \multicolumn{7}{|l|}{ Age categories. No (\%) } \\
\hline 18 to 39 years & $141(9)$ & $261(9)$ & $405(11)$ & $332(13)$ & $258(15)$ & $1397(11)$ \\
\hline 40 to 59 years & $675(41)$ & $1199(40)$ & $1465(40)$ & $1042(40)$ & $753(45)$ & $5134(41)$ \\
\hline 60 to 79 years & $743(45)$ & $1377(46)$ & $1629(44)$ & $1149(44)$ & $616(37)$ & $5514(43)$ \\
\hline 80 years and above & $106(6)$ & $185(6)$ & $213(6)$ & $114(4)$ & $62(4)$ & $680(5)$ \\
\hline \multicolumn{7}{|c|}{ Clinical covariates, Mean (SD) } \\
\hline $\mathrm{HbA} 1 \mathrm{c}(\%)$ & $8.6(1.9)$ & $8.6(1.8)$ & $8.7(1.8)$ & $8.8(1.9)$ & $8.8(1.8)$ & $8.7(1.8)$ \\
\hline BMI $\left(\mathrm{kg} / \mathrm{m}^{2}\right)$ & $21.8(2.8)$ & $27.7(1.4)$ & $32.5(1.4)$ & $37.2(1.4)$ & $44.1(4.3)$ & $32.7(6.9)$ \\
\hline Height (m) & $1.7(0.09)$ & $1.7(0.10)$ & $1.7(0.1)$ & $1.7(0.1)$ & $1.6(0.1)$ & $1.7(0.1)$ \\
\hline Weight (Kg) & $69.7(12.2)$ & $81.0(11.6)$ & $90.5(12.1)$ & $100.9(13.1)$ & $116.4(16.3)$ & $91.5(18.8)$ \\
\hline $\mathrm{DBP}(\mathrm{mmHg})$ & $75.6(11.1)$ & $76.3(10.9)$ & $76.3(10.6)$ & $77.1(11.0)$ & $77.6(10.7)$ & $76.6(10.9)$ \\
\hline $\mathrm{SBP}(\mathrm{mmHg})$ & $134.4(23.3)$ & $135.0(22.9)$ & $135.8(23.0)$ & $137.2(22.8)$ & $138.7(23.4)$ & $136.1(23.1)$ \\
\hline $\mathrm{TC}(\mathrm{mmol} / \mathrm{l})$ & $4.5(1.4)$ & $4.6(1.3)$ & $4.6(1.3)$ & $4.6(1.3)$ & $4.6(1.3)$ & $4.6(1.3)$ \\
\hline Triglyceride (mmol/L) & $1.8(1.2)$ & $2.0(1.2)$ & $2.0(1.2)$ & $2.1(1.2)$ & $2.2(1.2)$ & $2.0(1.2)$ \\
\hline $\mathrm{LDL}(\mathrm{mmol} / \mathrm{l})$ & $2.4(1.1)$ & $2.4(1.1)$ & $2.4(1.1)$ & $2.4(1.1)$ & $2.4(1.1)$ & $2.4(1.1)$ \\
\hline $\mathrm{HDL}(\mathrm{mmol} / \mathrm{l})$ & $1.3(0.5)$ & $1.3(0.4)$ & $1.3(0.4)$ & $1.2(0.5)$ & $1.2(0.4)$ & $1.3(0.5)$ \\
\hline Albumin (g/L) & $4.1(0.4)$ & $4.1(0.4)$ & $4.1(0.4)$ & $4.0(0.4)$ & $4.0(0.4)$ & $4.1(0.4)$ \\
\hline $\mathrm{ACR}(\mathrm{mg} / \mathrm{mol})$ & $4.7(8.2)$ & $5.6(8.5)$ & $5.6(8.4)$ & $5.9(8.6)$ & $6.0(8.5)$ & $5.6(8.5)$ \\
\hline eGFR $\left(\mathrm{mls} / \mathrm{min} / 1.73 \mathrm{~m}^{2}\right)$ & $66.4(20.9)$ & $65.2(20.9)$ & $65.1(21.1)$ & $64.6(21.5)$ & $64.3(21.5)$ & $65.1(21.2)$ \\
\hline Diabetes duration (yrs) & $3.9(5.0)$ & $3.7(5.0)$ & $3.9(5.0)$ & $3.7(4.6)$ & $3.8(4.6)$ & $3.8(4.9)$ \\
\hline
\end{tabular}

Lifestyle

Smoking status, No. (\%) 


\begin{tabular}{|c|c|c|c|c|c|c|}
\hline Non-smoker & $812(49)$ & $1536(51)$ & $2005(54)$ & $1403(53)$ & $930(55)$ & $6686(52)$ \\
\hline Ex-smoker & $570(34)$ & $1050(35)$ & $1179(32)$ & $840(32)$ & $538(32)$ & 4177 (33) \\
\hline Current smoker & $283(17)$ & $436(14)$ & $528(14)$ & $394(15)$ & $221(13)$ & $1862(15)$ \\
\hline \multicolumn{7}{|l|}{ Alcohol status, No. (\%) } \\
\hline Non-drinker & $453(27)$ & $880(29)$ & $1225(33)$ & $898(34)$ & $589(35)$ & $4045(32)$ \\
\hline Ex-drinker & $194(12)$ & $362(12)$ & 409 (11) & $310(12)$ & $178(11)$ & $1453(11)$ \\
\hline Current drinker & $1018(61)$ & $1780(59)$ & $2078(56)$ & $1429(54)$ & $922(55)$ & $7227(57)$ \\
\hline \multicolumn{7}{|l|}{ GLTs, No. (\%) } \\
\hline \multicolumn{7}{|l|}{ Insulin } \\
\hline Premix & $978(59)$ & $1783(59)$ & $2206(59)$ & $1470(56)$ & $933(55)$ & $7370(58)$ \\
\hline Basal-bolus & $687(41)$ & $1239(41)$ & $1506(41)$ & $1167(44)$ & $756(45)$ & $5355(42)$ \\
\hline Metformin & $1308(79)$ & $2496(83)$ & $3164(85)$ & $2333(88)$ & $1530(91)$ & $10831(85)$ \\
\hline Sulphonylurea & $1212(73)$ & $2186(72)$ & $2728(73)$ & $1952(74)$ & $1246(74)$ & $9324(73)$ \\
\hline Thiazolidinediones & $491(29)$ & $891(29)$ & $1172(32)$ & $878(33)$ & $622(37)$ & $4054(32)$ \\
\hline GLP-1RA & $159(10)$ & $281(9)$ & $431(12)$ & $371(14)$ & $289(17)$ & $1531(12)$ \\
\hline Gliptins & $220(13)$ & $412(14)$ & $545(15)$ & $391(15)$ & $273(16)$ & $1841(15)$ \\
\hline SGLT-2i & $6(0)$ & $19(1)$ & $16(0)$ & $18(1)$ & $12(1)$ & $71(1)$ \\
\hline Glinides & $70(4)$ & $116(4)$ & $176(5)$ & $115(4)$ & $85(5)$ & $562(4)$ \\
\hline \multicolumn{7}{|l|}{ Use of Medications, No. (\%) } \\
\hline Aspirin & $1572(90)$ & $2859(92)$ & $3519(98)$ & $2488(96)$ & $1584(96)$ & $12022(94)$ \\
\hline Antihypertensive & $1337(85)$ & $2498(87)$ & $3114(88)$ & $2183(88)$ & $1406(89)$ & $10538(83)$ \\
\hline LLTs & $1391(88)$ & $2566(90)$ & $3187(91)$ & $2238(90)$ & $1425(90)$ & $10807(85)$ \\
\hline \multicolumn{7}{|l|}{ Comorbidities, No. $(\%)^{\mathrm{c}}$} \\
\hline CHD & $196(12)$ & $380(13)$ & 447 (12) & $277(11)$ & $165(10)$ & $1465(12)$ \\
\hline PAD & $116(7)$ & $212(7)$ & $263(7)$ & $143(5)$ & $89(5)$ & 2137 (17) \\
\hline Heart Failure & $90(5)$ & $167(6)$ & $205(6)$ & $141(5)$ & $110(7)$ & $713(6)$ \\
\hline Hypoglycaemia & $286(17)$ & $500(17)$ & $670(18)$ & $445(17)$ & 236 (14) & 2137 (17) \\
\hline $\mathrm{CKD}\left(\mathrm{eGFR}<60 \mathrm{mls} / \mathrm{min} / 1.73 \mathrm{~m}^{2}\right)$ & $632(12)$ & 1207(24) & $1479(29)$ & $1075(21)$ & $702(14)$ & $5095(40)$ \\
\hline
\end{tabular}

Abbreviations:
BMI (body mass index); SBP (systolic blood pressure); DBP (diastolic blood pressure); HbAlc (haemoglobin Alc); HDL (high-density lipoprotein); LDL (lowdensity lipoprotein); TC (total cholesterol); eGFR (estimated glomerular filtration rate); LLTs (lipid lowering therapies); PAD (peripheral arterial disease); CHD (coronary heart disease); CKD (Chronic Kidney Disease); ACR (albumin creatinine ratio); GLTs (Glucose-lowering therapies); AMI (Acute myocardial infarction); SD (standard deviation). Diabetes duration is the time from first diagnosis of diabetes to date of insulin initiation (index date); GLP-1 (Glucagon like peptide-1); SGLT (sodium glucose co-transporter) 
Table 2 - Proportions and odds of achieving the NICE target $\mathrm{HbA} 1 \mathrm{c}$ of $\leq 7.5 \%$ ( $58 \mathrm{mmol} / \mathrm{mol}$ ) by the BMI categories.

\begin{tabular}{|c|c|c|c|c|c|c|c|c|c|c|c|c|}
\hline & \multicolumn{2}{|c|}{6 months } & \multicolumn{2}{|c|}{12 months } & \multicolumn{2}{|c|}{24 months } & \multicolumn{2}{|c|}{36 months } & \multicolumn{2}{|c|}{48 months } & \multicolumn{2}{|c|}{60 months } \\
\hline $\begin{array}{c}\text { BMI } \\
\text { categories at } \\
\text { baseline }\end{array}$ & $\begin{array}{c}\text { Prop } \\
(\%)\end{array}$ & $\begin{array}{c}\text { aOR* } \\
(95 \% \mathrm{CI})\end{array}$ & $\begin{array}{l}\text { Prop } \\
(\%)\end{array}$ & $\begin{array}{c}\text { aOR* } \\
(95 \% \mathrm{CI})\end{array}$ & $\begin{array}{c}\text { Prop } \\
(\%)\end{array}$ & $\begin{array}{c}\mathrm{aOR} * \\
(95 \% \mathrm{CI})\end{array}$ & $\begin{array}{c}\text { Prop } \\
(\%)\end{array}$ & $\begin{array}{c}\text { aOR* } \\
(95 \% \mathrm{CI})\end{array}$ & $\begin{array}{c}\text { Prop } \\
(\%)\end{array}$ & $\begin{array}{c}\text { aOR* } \\
(95 \% \mathrm{CI})\end{array}$ & $\begin{array}{c}\text { Prop } \\
(\%)\end{array}$ & $\begin{array}{c}\text { aOR* } \\
(95 \% \mathrm{CI})\end{array}$ \\
\hline Normal & 36.6 & ref & 37.0 & ref & 34.2 & ref & 34.1 & ref & 44.8 & ref & 45.6 & ref \\
\hline Overweight & 32.8 & $\begin{array}{c}0.86 \\
(0.75-0.98)\end{array}$ & 33.1 & $\begin{array}{c}0.85 \\
(0.75-0.97)\end{array}$ & 31.0 & $\begin{array}{c}0.87 \\
(0.76-0.99)\end{array}$ & 32.2 & $\begin{array}{c}0.95 \\
(0.83-1.08)\end{array}$ & 44.9 & $\begin{array}{c}0.99 \\
(0.87-1.12)\end{array}$ & 44.4 & $\begin{array}{c}0.95 \\
(0.84-1.08)\end{array}$ \\
\hline $\begin{array}{l}\text { Obese } \\
\text { Class I }\end{array}$ & 31.0 & $\begin{array}{c}0.80 \\
(0.71-0.91)\end{array}$ & 31.6 & $\begin{array}{c}0.78 \\
(0.70-0.91)\end{array}$ & 30.7 & $\begin{array}{c}0.87 \\
(0.77-0.99)\end{array}$ & 33.2 & $\begin{array}{c}1.01 \\
(0.88-1.15)\end{array}$ & 45.7 & $\begin{array}{c}1.00 \\
(0.89-1.14)\end{array}$ & 45.9 & $\begin{array}{c}0.98 \\
(0.86-1.10)\end{array}$ \\
\hline $\begin{array}{l}\text { Obese } \\
\text { Class II }\end{array}$ & 30.0 & $\begin{array}{c}0.78 \\
(0.68-0.90)\end{array}$ & 31.6 & $\begin{array}{c}0.81 \\
(0.70-0.93)\end{array}$ & 29.4 & $\begin{array}{c}0.83 \\
(0.72-0.95)\end{array}$ & 31.4 & $\begin{array}{c}0.95 \\
(0.83-1.10)\end{array}$ & 47.6 & $\begin{array}{c}1.08 \\
(0.95-1.23)\end{array}$ & 45.2 & $\begin{array}{c}0.93 \\
(0.82-1.06)\end{array}$ \\
\hline \multirow[t]{2}{*}{$\begin{array}{l}\text { Obese } \\
\text { Class III }\end{array}$} & 27.8 & $\begin{array}{c}0.69 \\
(0.59-0.80)\end{array}$ & 30.0 & $\begin{array}{c}0.73 \\
(0.62-0.85)\end{array}$ & 30.9 & $\begin{array}{c}0.91 \\
(0.78-1.06)\end{array}$ & 32.5 & $\begin{array}{c}1.03 \\
(0.88-1.21)\end{array}$ & 47.1 & $\begin{array}{c}1.07 \\
(0.93-1.24)\end{array}$ & 46.4 & $\begin{array}{c}0.99 \\
(\mathbf{0 . 8 5}-1.14)\end{array}$ \\
\hline & $\begin{array}{c}\mathbf{p}< \\
0.0001 * *\end{array}$ & $\begin{array}{c}\text { LRT } \\
\text { p-value**** } \\
\text { 0.0001 } \\
\end{array}$ & $\begin{array}{c}\mathrm{p}< \\
0.0001\end{array}$ & $\begin{array}{c}\text { LRT } \\
\text { p-value } \\
\text { 0.0011 } \\
\end{array}$ & $\begin{array}{c}\mathbf{p}= \\
\mathbf{0 . 0 2 3}\end{array}$ & $\begin{array}{c}\text { LRT } \\
\text { p-value } \\
0.2519 \\
\end{array}$ & $\mathbf{p}=\mathbf{0 . 3 7 7}$ & $\begin{array}{c}\text { LRT } \\
\text { p-value } \\
0.6366 \\
\end{array}$ & $p=0.160$ & $\begin{array}{c}\text { LRT } \\
\text { p-value } \\
0.4653 \\
\end{array}$ & $p=0.942$ & $\begin{array}{c}\text { LRT } \\
\text { p-value } \\
0.8255 \\
\end{array}$ \\
\hline \multicolumn{13}{|c|}{$\begin{array}{l}\text { Abbreviations: BMI (body mass index); Prop (Proportion in \%); } \\
* \text { aOR = Adjusted Odds Ratio. Adjusted for age, duration of diabetes, gender, socioeconomic status (measured by Townsend Deprivation scores); smoking status, diastolic and systolic blood pressure } \\
\text { and insulin-regimen } \\
\text { ** p-value of the proportions at the follow-up timeline } \\
* * * \text { LRT (Likelihood Ratio Test) p-value showing } \\
\text { p-value for trend }<0.0001 \text { and } 0.001 \text { at } 6 \text { and } 12 \text { months respectively but not significant }(>0.05) \text { at } 24,36,48 \text { and } 60 \text { months }\end{array}$} \\
\hline
\end{tabular}


Table 3 - Mean follow-up BMI and mean coefficients of change in BMI compared to the normal BMI category

\begin{tabular}{|c|c|c|c|c|c|c|c|c|c|c|c|c|}
\hline \multirow[b]{2}{*}{$\begin{array}{l}\text { BMI categories } \\
\text { at baseline }\end{array}$} & \multicolumn{2}{|c|}{6 months } & \multicolumn{2}{|c|}{12 months } & \multicolumn{2}{|c|}{24 months } & \multicolumn{2}{|c|}{36 months } & \multicolumn{2}{|c|}{48 months } & \multicolumn{2}{|c|}{60 months } \\
\hline & $\begin{array}{c}\text { Mean } \\
\text { BMI } \\
\left(\mathbf{k g} / \mathbf{m}^{2}\right)\end{array}$ & $\begin{array}{l}\text { Coefff* } \\
(95 \% \mathrm{CI})\end{array}$ & $\begin{array}{c}\text { Mean } \\
\text { BMI } \\
\left(\mathbf{k g} / \mathbf{m}^{2}\right)\end{array}$ & $\begin{array}{c}\text { Coefff* } \\
(95 \% \text { CI })\end{array}$ & $\begin{array}{c}\text { Mean } \\
\text { BMI } \\
\left(\mathrm{kg} / \mathrm{m}^{2}\right)\end{array}$ & $\begin{array}{l}\text { Coefff* } \\
(95 \% \mathrm{CI})\end{array}$ & $\begin{array}{c}\text { Mean } \\
\text { BMI } \\
\left(\mathbf{k g} / \mathbf{m}^{2}\right)\end{array}$ & $\begin{array}{l}\text { Coefff* } \\
(95 \% \mathrm{CI})\end{array}$ & $\begin{array}{c}\text { Mean } \\
\text { BMI } \\
\left(\mathbf{k g} / \mathbf{m}^{2}\right)\end{array}$ & $\begin{array}{l}\text { Coefff* } \\
(95 \% \mathrm{CI})\end{array}$ & $\begin{array}{c}\text { Mean } \\
\text { BMI } \\
\left(\mathbf{k g} / \mathbf{m}^{2}\right)\end{array}$ & $\begin{array}{l}\text { Coefff* } \\
(95 \% \mathrm{CI})\end{array}$ \\
\hline Normal & 22.7 & ref & 23.3 & ref & 25.3 & ref & 26.2 & ref & 26.8 & ref & 28.2 & ref \\
\hline Overweight & 28.0 & $\begin{array}{c}-0.52 \\
(-0.65,-0.39)\end{array}$ & 28.3 & $\begin{array}{c}-0.77 \\
(-0.96,-0.59)\end{array}$ & 29.2 & $\begin{array}{c}-1.93 \\
(-2.28,-1.59)\end{array}$ & 29.6 & $\begin{array}{c}-2.52 \\
(-2.90,-2.14)\end{array}$ & 29.9 & $\begin{array}{c}-2.95 \\
(-3.35,-2.56)\end{array}$ & 30.5 & $\begin{array}{c}-3.72 \\
(-4.12,-3.31)\end{array}$ \\
\hline $\begin{array}{l}\text { Obese } \\
\text { Class I }\end{array}$ & 32.6 & $\begin{array}{c}-0.78 \\
(-0.90,-0.65)\end{array}$ & 32.5 & $\begin{array}{c}-1.38 \\
(-1.56,-1.21)\end{array}$ & 32.4 & $\begin{array}{c}-3.83 \\
(-4.17,-3.50)\end{array}$ & 32.3 & $\begin{array}{c}-4.88 \\
(-5.25,-4.51)\end{array}$ & 32.2 & $\begin{array}{c}-5.65 \\
(-6.04,-5.27)\end{array}$ & 32.7 & $\begin{array}{c}-6.59 \\
(-6.99,-6.20)\end{array}$ \\
\hline $\begin{array}{c}\text { Obese } \\
\text { Class II }\end{array}$ & 37.0 & $\begin{array}{c}-1.03 \\
(-1.17,-0.90)\end{array}$ & 36.8 & $\begin{array}{c}-1.84 \\
(-2.03,-1.65)\end{array}$ & 36.0 & $\begin{array}{c}-4.94 \\
(-5.30,-4.59)\end{array}$ & 35.7 & $\begin{array}{c}-6.33 \\
(-6.72,-5.93)\end{array}$ & 35.1 & $\begin{array}{c}-7.66 \\
(-8.07,-7.25)\end{array}$ & 35.2 & $\begin{array}{c}-9.11 \\
(-9.53,8.69)\end{array}$ \\
\hline \multirow[t]{2}{*}{$\begin{array}{l}\text { Obese } \\
\text { Class III }\end{array}$} & 43.7 & $\begin{array}{c}-1.33 \\
(-1.48,-1.18)\end{array}$ & 43.0 & $\begin{array}{c}-2.64 \\
(-2.85,-2.43)\end{array}$ & 41.1 & $\begin{array}{c}-6.92 \\
(-7.32,-6.52)\end{array}$ & 40.0 & $\begin{array}{c}-9.03 \\
(-9.47,-8.58)\end{array}$ & 38.5 & $\begin{array}{c}-11.18 \\
(-11.6,-10.7)\end{array}$ & 38.4 & $\begin{array}{c}-12.89 \\
(-13.4,-12.42)\end{array}$ \\
\hline & & $\begin{array}{c}\text { LRT } \\
\text { p-value** } \\
<0.00001\end{array}$ & & $\begin{array}{c}\text { LRT } \\
\text { p-value } \\
0.00001\end{array}$ & & $\begin{array}{c}\text { LRT } \\
\text { p-value } \\
<0.00001\end{array}$ & & $\begin{array}{c}\text { LRT } \\
\text { p-value } \\
<0.00001\end{array}$ & & $\begin{array}{c}\text { LRT } \\
\text { p-value } \\
<0.00001\end{array}$ & & $\begin{array}{c}\text { LRT } \\
\text { p-value } \\
<0.00001\end{array}$ \\
\hline $\begin{array}{l}\text { Abbreviations: BMI } \\
*^{*} \text { Mean coefficient o } \\
* * \text { * } \\
\text { p-value for for trend }<0\end{array}$ & $\begin{array}{l}\text { tody mass } \\
\text { hange ion } \\
\text { tio Test) } p \\
\text { oo1 for eac }\end{array}$ & $\begin{array}{l}\text { ndex) } \\
\text { BMI compared to } \\
\text { value showing the } \\
\text { h follow up timeli }\end{array}$ & $\begin{array}{l}\text { norm } \\
\text { an ch }\end{array}$ & I category & 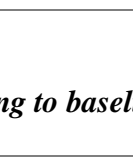 & BMI categories & & & & & & \\
\hline
\end{tabular}


Table 4: Events, rates and hazard ratios of composite MACE and subgroup of all-cause mortality, non-fatal MI and stroke by baseline BMI categories.

\begin{tabular}{|c|c|c|c|c|c|c|}
\hline & $\begin{array}{l}\text { Normal } \\
(n=1665)\end{array}$ & $\begin{array}{c}\text { Overweight } \\
(n=3022)\end{array}$ & $\begin{array}{c}\text { Obese Class I } \\
\quad(n=3712)\end{array}$ & $\begin{array}{c}\text { Obese Class II } \\
\quad(n=2637)\end{array}$ & $\begin{array}{c}\text { Obese Class III } \\
(n=1689)\end{array}$ & $\begin{array}{c}\text { Total } \\
(\mathrm{n}=12,725)\end{array}$ \\
\hline \multicolumn{7}{|l|}{ Composite Outcome ${ }^{\mathrm{a}}$} \\
\hline No of events/person-years & $143 / 6,508$ & $284 / 11,694$ & $320 / 14,542$ & $201 / 10,275$ & $147 / 6,495$ & $1095 / 49,516$ \\
\hline Composite event rates ${ }^{\mathrm{b}}(95 \% \mathrm{CI})$ & $22.0(18.6-25.9)$ & $24.3(21.6-27.3)$ & $22.0(19.7-24.6)$ & $19.6(17.0-22.5)$ & $22.6(19.3-26.6)$ & $22.1(20.8-23.5)$ \\
\hline Adjusted $\mathrm{HR}^{\mathrm{c}}(95 \% \mathrm{CI})$ & ref & $1.10(0.90-1.35)$ & $1.05(0.86-1.29)$ & $1.03(0.83-1.29)$ & $1.30(1.02-1.66)$ & - \\
\hline \multicolumn{7}{|l|}{ Composite Cardiovascular event $^{\mathrm{d}}$} \\
\hline No of events/person-years & $70 / 6510$ & $143 / 11,701$ & $150 / 14,549$ & $81 / 10,280$ & $56 / 6,499$ & $500 / 49,541$ \\
\hline $\mathrm{CV}$ event rates ${ }^{\mathrm{b}}(95 \% \mathrm{CI})$ & $10.8(8.5-13.6)$ & $12.2(10.4-14.4)$ & $10.3(8.8-12.1)$ & $7.9(6.3-9.8)$ & $8.6(6.6-11.2)$ & $10.1(9.2-11.0)$ \\
\hline Adjusted $\mathrm{HR}^{\mathrm{c}}(95 \% \mathrm{CI})$ & ref & $1.25(0.86-1.81)$ & $1.21(0.73-2.02)$ & $0.99(0.49-1.97)$ & $1.34(0.53-3.40)$ & - \\
\hline \multicolumn{7}{|l|}{ All-cause mortality } \\
\hline No of events/person-years & $73 / 6,667$ & $141 / 12,007$ & $169 / 14,868$ & $119 / 10,445$ & $90 / 6,612$ & $592 / 50,601$ \\
\hline Mortality rates ${ }^{\mathrm{b}}(95 \% \mathrm{CI})$ & $10.9(8.7-13.8)$ & $11.7(10.0-13.8)$ & $11.4(9.8-13.2)$ & $11.4(9.5-13.6)$ & $13.6(11.1-16.7)$ & $11.7(10.8-12.7)$ \\
\hline Adjusted $\mathrm{HR}^{\mathrm{c}}(95 \% \mathrm{CI})$ & ref & $1.09(0.81-1.45)$ & $1.12(0.84-1.49)$ & $1.31(0.96-1.77)$ & $1.75(1.26-2.43)$ & - \\
\hline \multicolumn{7}{|c|}{ Non-fatal Acute Myocardial Infarction (AMI) } \\
\hline No of events/person-years & $13 / 6,639$ & $21 / 11,960$ & $20 / 14,828$ & $8 / 10,434$ & $3 / 6,610$ & $65 / 50,472$ \\
\hline AMI event rates ${ }^{b}(95 \% \mathrm{CI})$ & $2.0(1.1-3.4)$ & $1.8(1.1-2.7)$ & $1.3(0.9-2.1)$ & $0.8(0.4-1.5)$ & $0.5(0.1-1.4)$ & $1.3(1.0-1.6)$ \\
\hline Adjusted $\mathrm{HR}^{\mathrm{c}}(95 \% \mathrm{CI})$ & ref & $1.40(0.51-3.84)$ & $2.24(0.53-9.48)$ & $1.76(0.23-13.3)$ & $2.94(0.19-46.0)$ & - \\
\hline \multicolumn{7}{|l|}{ Non-fatal Stroke } \\
\hline No of events/person-years & $57 / 6,541$ & $122 / 11,755$ & $130 / 14,597$ & $73 / 10,295$ & $53 / 6,505$ & $435 / 49,695$ \\
\hline Stroke event rates ${ }^{\mathrm{b}}(95 \% \mathrm{CI})$ & $8.7(6.7-11.3)$ & $10.4(8.7-12.4)$ & $8.9(7.5-10.6)$ & $7.1(5.6-8.9)$ & $8.1(6.2-10.7)$ & $8.8(8.0-9.6)$ \\
\hline Adjusted $\mathrm{HR}^{\mathrm{c}}(95 \% \mathrm{CI})$ & ref & $1.25(0.84-1.87)$ & $1.13(0.66-1.95)$ & $0.92(0.45-1.92)$ & $1.17(0.44-3.16)$ & - \\
\hline $\begin{array}{l}\text { a Composite outcome is a three-point MACE it } \\
b \text { Rates at } 1000 \text { person-years. } 95 \% \text { CI- } 95 \% \text { c } \\
\text { c aHR (Adjusted Hazard Ratio). Adjusted for a } \\
\text { filtration rate, lipid profile (total cholesterol, } l \\
d \text { Composite Cardiovascular event is a two-po }\end{array}$ & ng all-cause mortalit & 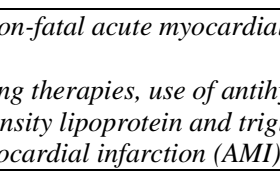 & retion (A $M D)$ and & troke & Non & rular \\
\hline
\end{tabular}

